\title{
Article \\ Temperature Variation and Climate Resilience Action within a Changing Landscape
}

\author{
Leah Marajh * and Yuhong He
}

check for

updates

Citation: Marajh, L.; He, Y.

Temperature Variation and Climate Resilience Action within a Changing Landscape. Remote Sens. 2022, 14, 701 https://doi.org/10.3390/rs14030701

Academic Editor: Hirohiko Nagano

Received: 17 December 2021

Accepted: 30 January 2022

Published: 2 February 2022

Publisher's Note: MDPI stays neutral with regard to jurisdictional claims in published maps and institutional affiliations.

Copyright: (C) 2022 by the authors. Licensee MDPI, Basel, Switzerland. This article is an open access article distributed under the terms and conditions of the Creative Commons Attribution (CC BY) license (https:// creativecommons.org/licenses/by/ $4.0 /)$.
Department of Geography, Geomatics and Environment, University of Toronto Mississauga, 3359 Mississauga Road, Mississauga, ON L5L 1C6, Canada; yuhong.he@utoronto.ca

* Correspondence: leah.marajh@utoronto.ca

\begin{abstract}
Temperature change can have profound impacts on livelihood activities and human wellbeing. Specific factors such as land transitions and climate knowledge can influence temperature variation and actions for adaptation. In addition to meteorological data, this study integrates land surface temperature (LST) derived from satellite imagery and local temperature perceptions obtained through interviews to advance a deeper understanding of spatial temperature and its impacts, which is not often seen within climate studies. This study examines local temperature across three different land types (rural mountains, rural agricultural lowlands, urban areas) in the Greater Angkor Region of Cambodia to highlight important insights about temperature and climate resilience action. The results revealed that changes in temperature were most pronounced in Phnom Kulen National Park (rural mountain) and in the rural agricultural lowlands, where residents discussed direct impacts and disruptions to their lives. Temperature, in both the LST results and through local perceptions, demonstrated a strong correlation to ground features, where areas with low vegetation exhibited high temperatures and areas with high vegetation observed low temperatures. While climate action in the form of tree planting and forest conservation are major climate mitigation strategies being undertaken in this region, social awareness and the ability to adapt to changes in temperature was revealed to be uneven across the landscape, suggesting that local entities should mobilize around gaining more education and training for all residents.
\end{abstract}

Keywords: temperature; Landsat; LST; NDVI; perceptions; climate resilience

\section{Introduction}

Changes in climate can have profound impacts on people and their environments. Climate changes and, particularly, global warming, have largely been attributed to anthropogenic factors [1,2]. According to the Intergovernmental Panel on Climate Change [2] (p. 4), humans "have caused approximately $1.0^{\circ} \mathrm{C}$ of global warming above pre-industrial levels", with future projections suggesting further increases. Risks associated with climate changes are widely influenced by exposure and vulnerability, which vary across spatial and temporal scales depending on factors such as land types, livelihoods, and resources [1]. For example, rural-urban transitions, economic development, and landscape conversions all factor into vulnerability and exposure to climate change [1,2]. While average climate variation exhibits rising and less cool temperatures [3,4], extreme climate events, such as severe heat, torrential rainfall, and drought, are occurring more frequently [5]. The degree to which changes in social-ecological landscapes exacerbate temperature conditions and impact human well-being still requires more investigation, especially in areas of the lower-latitude countries, where vulnerabilities are the most pronounced [6-8]. Specifically, lower-latitude countries bear the least responsibility for changes to climate, yet experience the most severe impacts such as greater food insecurity and livelihood disruptions with the lowest capacity to adapt $[9,10]$. 
Research into climate change identifies patterns and approaches to limit the impact of climate risks. Integrative methods that incorporate natural and human systems are particularly important as they increase understanding of the drivers and impacts that inform decision making. According to the National Research Council [11], integrative approaches for sustainability science are fundamental for knowledge and action, and researchers should focus on integrating different branches of knowledge across multiple scalar dimensions with diverse methods and designs. A social-ecological systems framework describes the interconnections between humans and nature [12]. It is a coupled system that comprises feedbacks and interactions between people and their environment, with the main concern of trying to make systems more resilient. It considers long time scales and cross-scale interactions, which provide important information for addressing climate change based on scientific data and historical analysis [13]. The examining of these time scales (decades) can offer key insights into how climate and environmental systems have changed over time [2].

The multiple dimensions of changing climate conditions are challenging for both scholars and residents to understand. Often, changes develop through slow processes that occur over long time periods where, for many, tangible evidence can vary quite considerably [14]. The combination, therefore, of both quantitative and qualitative climate data is essential for quantifying and understanding these changes. Quantitative climate data includes figures and numbers, and attempts to quantify climate change, while qualitative climate data comprises the experiences of climate change to understand its impacts.

Quantitative climate data are represented through various forms, including meteorological data and geospatial data. A common geospatial dataset, land surface temperature (LST) data, derived from remote sensing images, describing how hot the Earth's surface is, has become an essential tool for measuring temperature over different land types $[15,16]$. Surface temperature maps are processed from the thermal infrared (TIR) bands. These surface temperature maps can provide extensive information regarding spatial variations in temperature, but more importantly, they can advance understanding of temperature dynamics when linked to ground features such as vegetation $[17,18]$. Recent studies connecting LST with vegetation have emphasized the importance of examining the role of land transitions and vegetation dynamics in influencing regional climate [19-22].

Qualitative climate data typically includes perceptions and experiences of climate change garnered from residents. Perceptions of climate can differ for people depending on socioeconomic background and services or resources available [14]. Perception data are particularly important in areas where data from weather stations may be scarce and/or difficult to acquire, and especially when data are needed for different land types. Perceptions, therefore, provide local knowledge and understanding in relation to how particular environments and social-ecological systems function and ultimately change over time [23].

Climate resilience is the ability to prepare and manage for disruptions related to climate change [24]. Managing resilience within a climate context is primarily grounded in the notion that we live with uncertainty-things are constantly changing and adapting to those changes is how we maintain and enhance resilience [25]. Resilience describes the capacity of a system to face disturbances yet remain functioning [26,27]. Climate resilience strategies aim to address both short-term and long-term climate concerns. They focus on being able to adjust to changes, operationalize pathways for learning, and adapt to enhance resilience [28]. Challenges in applying climate resilience, however, arise through uneven processes of learning and access to knowledge as well as a lack of empirical data; this is particularly salient when analysis limits or marginalizes the voices and opinions of local people, which are particularly important for understanding the capacity for adaptation [29].

This study advances understandings of temperature change using an integrated approach based on spatial temperature within a diverse landscape that includes, rural mountains, rural agricultural lowlands, and urban areas. The main research questions are: (1) How and why is temperature changing? (2) Are people able to adapt and enact climate resilience strategies? (3) What recommendations are needed for improving climate action? The study contributes to insights that elucidate the ways in which climate resilience 
action is experienced among different groups of people, which is important for developing more tailored climate resilience strategies. It also provides an in-depth analysis of spatial temperature using remote sensing and in situ data (meteorological and interviews) that is not seen in many studies. In this paper, a spatial and temporal examination of temperature in the Greater Angkor Region of Cambodia demonstrates the impacts and actions that have occurred over the last 20 years. The methodology of this study combines multiple datasets to portray temperature in the region. The analysis correlates temperature with ground features and provides insights into livelihood impacts. A broader discussion on climate resilience action, particularly in relation to awareness and adaptation, is provided for future planning initiatives.

\section{Materials and Methods}

\subsection{Climate Conditions}

In Southeast Asia, over the last 50 years, climate change has intensified, with an increasing number of hot days and more frequent drought and flooding events [4]. Significant changes in climate represent threats to long term stability for many in this region, especially for those involved in the agricultural sector and who live near the poverty line $[9,10]$. Climate change in Southeast Asia is a complex issue, as a large portion of greenhouse gas emissions come from high emitter countries such as China and the United States [30]. In addition to this, countries in Southeast Asia must find a way to balance economic development, which is largely driven by land changes including deforestation, agricultural expansion, and urbanization that contribute to global warming, with sustainability [2].

Cambodia is a country that regularly experiences significant climate impacts, such as floods and droughts [31]. Since the early 2000s, Cambodia has been involved in climate action to help mitigate both acute and chronic climate events [32]. Cambodia's Climate Change Strategic Plan (2014-2023) identified a framework to develop Cambodia as a green, climate resilient society with goals to reduce climate vulnerabilities, transition to green approaches, and increase knowledge and engagement [33]. The long-term goal of the plan is to extend successful climate actions and mainstream climate resilience and awareness to sub-national levels [32,33]. However, despite multiple sources of funding (government, external, and private sector), climate resilience remains costly, and many action plans continue to be unfunded [32].

Located in northwestern Cambodia is the Greater Angkor Region (Figure 1), a diverse and transitional landscape that has experienced significant land changes. These changes particularly focus on deforestation, agricultural expansion, and urbanization, yet studies on climate and land interactions are very limited in range and time for this area. Two recent studies, by Chim et al. [34,35], focus on the present and future climate conditions at the World Heritage site of Angkor and the upper Siem Reap catchment area, but most climate studies in this area focus on historical climate accounts, perhaps because the past has many implications for the future [36,37]. In the 13th century C.E., a climatic shift occurred consisting of intense rainfall and drought $[38,39]$. While this was a large-scale change that resulted from amplified levels of volcanic activity and less solar energy [38], the coupling of landscape changes similar to present-day land conditions, such as the overuse of forested areas, agricultural expansion, rising population, and increase in urban sprawl $[38,40]$, makes this area a particularly compelling and underutilized study site for researching temperature among different land types.

Research was conducted in a subset of the Greater Angkor Region, where the main land types include mountains to the north (Phnom Kulen National Park (PKNP)), the urban centre to the south (Siem Reap City), and rural agricultural lowlands throughout much of the study site between the urban centre and the mountains [41,42]. The city of Siem Reap is an urbanizing tourist hub that has undergone both population and geographical expansion in addition to infrastructure development in recent years [43,44]. Approximately $40 \mathrm{~km}$ north of Siem Reap City is Phnom Kulen National Park, a mountain measuring about $25 \mathrm{~km} \times 15 \mathrm{~km}$ and rising $490 \mathrm{~m}$ above the lowlands [45,46]. The rural agricultural 
lowlands predominately feature rice cultivation and other crops that are planted throughout the year [47].
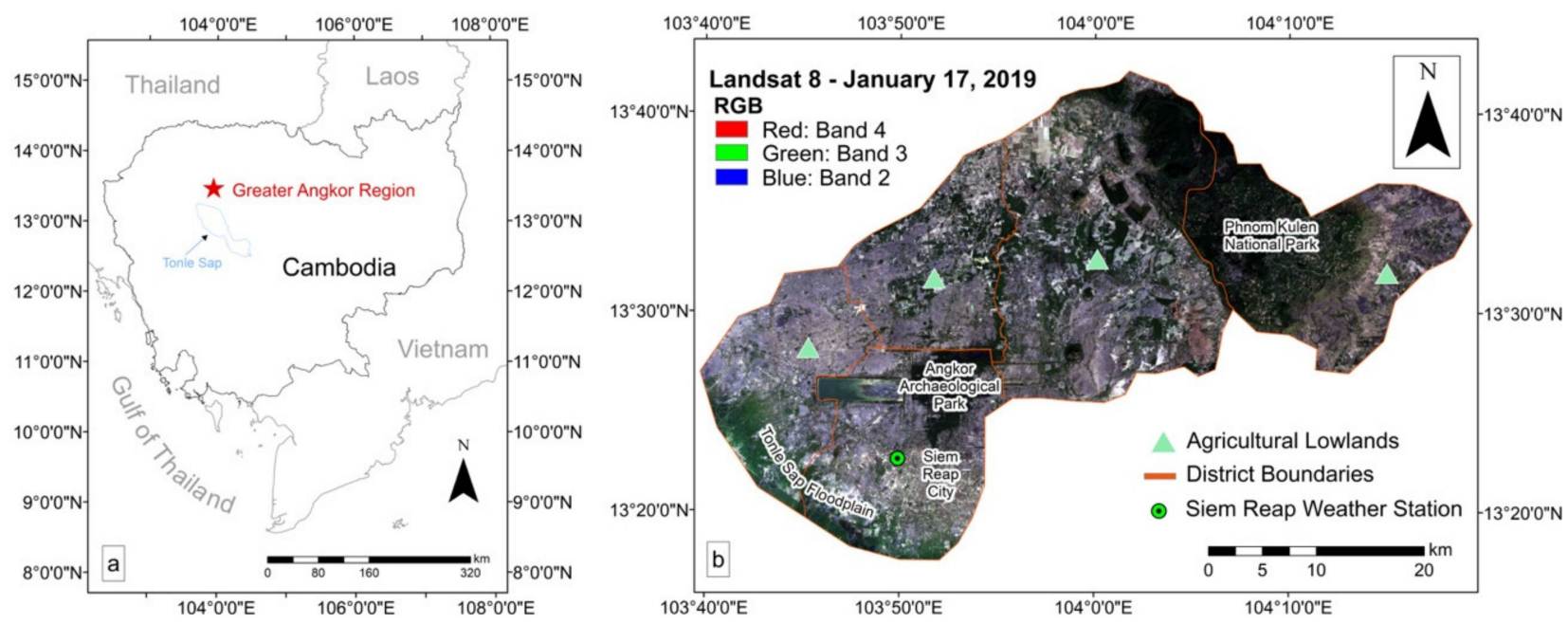

Figure 1. (a) Regional context depicting the study area in Cambodia (b) An RGB Landsat image highlighting important places and the location of the Siem Reap weather station.

This region features a seasonal monsoon climate influenced by monsoon winds $[38,40,41,48]$. Monsoon climates are denoted by wet and dry seasons, where the southwest monsoon marks the beginning of the wet season, and the northeast monsoon signals the start of the dry season $[41,48]$. Typically, the wet monsoon season starts in May until the end of October, while the dry monsoon season starts in November and lasts until April [48]. Rainfall is quite diverse throughout the region, with high rates towards the north (Kulen) and low rates towards the south (Tonle Sap) [31,41,48]. Average annual precipitation typically ranges between 1050 to $1800 \mathrm{~mm}$ but can vary from year to year [49]. On average, the area over the Tonle Sap floodplain experiences the least amount of rainfall at approximately $1180 \mathrm{~mm}$ [48], while central Angkor and the city of Siem Reap receives rainfall within a 1425-1475 mm range with higher amounts in PKNP reaching approximately $1850 \mathrm{~mm}(34-35,48]$. The average temperature of the region is $28^{\circ} \mathrm{C}$ [48], with minimum and maximum averages at Siem Reap ranging between $24^{\circ} \mathrm{C}$ to $34^{\circ} \mathrm{C}[34,35]$.

\subsection{Remote Sensing and Image Processing}

The quantitative analysis relied on well-known sources. Landsat Collection 1 surface reflectance tier 1 images from Google Earth Engine (GEE) were used for computing Land Surface Temperature (LST). The images are atmospherically corrected by the United States Geological Survey (USGS). The thermal bands are processed to brightness temperature and resampled to $30 \mathrm{~m}$ resolution by the USGS. These images are from the dry season and span over 20 years -7 January 1998, 21 January 2009, and 17 January 2019. The 1998 and 2009 images are from Landsat 5-TM, and the 2019 image is from Landsat 8-OLI/TIRS. To obtain LST, the open-source GEE code developed by Ermida et al. [50] was used. The code used the Statistical Mono-Window (SMW) algorithm and the same calibration process to provide consistency between the different Landsat satellites. It also used additional datasets important for deriving LST, including atmospheric data and surface emissivity data. For Landsat 5-TM, thermal band 6 was used, and from Landsat 8-OLI/TIRS, thermal band 10 was used. To compute LST, the code loaded the Landsat collection with user-selected date and region, emissivity data, and total column water vapour data. It then processed normalized difference vegetation index converted to fractional vegetation cover, and bare ground emissivity. The code merged these outputs to calculate TIR emissivity and finally compute LST. Ermida et al. [50] conducted a validation analysis using in situ LST data and derived overall accuracy of $0.5 \mathrm{~K}$ for Landsat 5 -TM and $0.2 \mathrm{~K}$ for Landsat 8-OLI/TIRS. 
The final images were calculated in Kelvin and converted to Celsius in ArcGIS (Esri, Redlands, California, USA) by subtracting 273.15.

NDVI is Normalized Difference Vegetation Index, a commonly used vegetation greenness index calculated from Level 2 Landsat images that were downloaded from https:/ / earthexplorer.usgs.gov (accessed on 20 May 2020). Landsat Level 2 optical bands are geometrically and atmospherically corrected; therefore, NDVI was directly calculated from the relative bands in ArcGIS (Esri, Redlands, California, USA). Specifically, band 3 (red) and band 4 (near-infrared) from the 1998 and 2009 Landsat 5-TM and band 4 (red) and band 5 (near-infrared) from the 2019 Landsat 8-OLI/TIRS were used to calculate NDVI based on the equation-(NIR - Red)/(NIR + Red). NDVI values range between -1 to 1 , where NDVI values of $<0.2$ represent bare soil and impervious features, and NDVI values of $>0.5$ represent full and densely vegetated areas [51]. NDVI was suitable for the purposes of this study because the focus is more on the image of deforestation or vegetation removal on temperature, and NDVI values $>0.6$ are not further separated to identify the impact of vegetation on temperature, and therefore the image of NDVI saturation issues is minimized.

\subsection{Climate Data}

Specific meteorological data for the Siem Reap weather station were obtained from Cambodia's Ministry of Water Resources and Meteorology and the Siem Reap Provincial Department of Water Resources and Meteorology. The Siem Reap weather station is located on the grounds of the provincial department and is close to Siem Reap City (see Figure 1b). As a result of different land types exhibiting different climate dynamics in this region, this station cannot provide precise temperature data for the whole region, but its data represent temperature information in the city and its surrounding areas. Temperature datasets provided measurements for each year between 1998 and 2019 inclusive. Tmax (the maximum temperature) for 7 January 1998, 21 January 2009, and 17 January 2019, were used as an in situ air temperature reference.

\subsection{Ground Points and Regression Analysis}

Ground points representing dominant landscape features were collected within the study area. They are assigned into four categories: densely vegetated areas, sparsely vegetated areas, seasonal agriculture, and impervious areas (urban). These points were collected during fieldwork in 2019, validated and edited using google earth imagery. To determine the corresponding landscape features for the years 1998 and 2009, the points were compared against historic maps and google earth imagery. The number of sampling points differed among years as a result of significant land transitions seen in the study area (see Table 1).

Table 1. Ground points represented by different land types for 1998, 2009, and 2019.

\begin{tabular}{lllllll}
\hline & $\mathbf{1 9 9 8}$ & & $\mathbf{2 0 0 9}$ & & $\mathbf{2 0 1 9}$ \\
\hline & \# of Points & \% of Points & \# of Points & \% of Points & \# of Points & \% of Points \\
Densely Vegetated Areas & 60 & $40.8 \%$ & 53 & $36.1 \%$ & 43 & $29.3 \%$ \\
Sparsely Vegetated Areas & 36 & $24.5 \%$ & 25 & $17.0 \%$ & 18 & $12.2 \%$ \\
Seasonal Agriculture & 28 & $19.0 \%$ & 33 & $22.4 \%$ & 46 & $31.3 \%$ \\
Impervious Areas (Urban) & 23 & $15.6 \%$ & 36 & $24.5 \%$ & 40 & $27.2 \%$ \\
\hline
\end{tabular}

The location of the ground points was used to extract the values from the NDVI and LST maps for all three years. A simple linear regression model was established between the NDVI (the independent variable) and the LST (the dependent variable) in each imaging year to determine the relationship between vegetation and temperature. The coefficient of determination $\left(R^{2}\right.$, range $\left.0-1\right)$ can be used to examine how much change in the dependent variable can be explained by the independent variable. The slope of the regression model estimates an average rate of change in temperature (LST) as a function of the change in vegetation (NDVI). 


\subsection{Interviews and Analysis}

Interviews with local people were conducted across the region in areas that were representative of the three land types (rural mountains, rural agricultural lowlands, urban areas) to collect information that can be described as perception data. Interviews took place in 2019 during the dry season. Sixty-five interviews were conducted with individuals ranging from residents, village leaders, commune chiefs, district governors, provincial and national departments, local and foreign entrepreneurs, and NGOs. Interviews were conducted through convenience and snowball sampling with most residents, while purposive sampling was used with key informants. Ethics approval to conduct interviews was obtained from the University of Toronto Research Ethics Board, which detailed obtaining full consent from respondents and providing anonymity to protect individual identities. Approval to conduct research was also obtained from the Siem Reap Province and the Ministry of Environment in Cambodia.

As PKNP has experienced significant natural forest cover loss in recent years, understanding perceptions from before and after the changes was particularly important for this area. Interviews were conducted in four different rural areas and one urban area to determine if climate perceptions were consistent or inconsistent across multiple locations. The urban area is essentially limited to the city of Siem Reap. Here, interviews were mostly conducted in the downtown area of the city. The main topics pertaining to this study included questions about (1) overall temperature perceptions for the area, (2) if notable changes fell outside of typical climate fluctuations, (3) what reasons were given for these changes, if any and, (4) what actions need to be taken to mitigate climate risks. These interviews function as a source of validation for the LST results, as residents in different areas can provide perceptions of changes in temperature over time.

Interviews in Khmer were conducted with the help of a Cambodian research assistant who asked questions and provided translations throughout the interview process. With the permission of the respondents, interviews were audio-recorded and later transcribed. Khmer interviews were transcribed to English using a second research assistant. Transcriptions of interviews were analyzed in NVivo (QSR International, Melbourne, Australia) and coded into themes that included climate, environmental change, climate-environmental impacts, and knowledge and support. Interviews ranged between 30-90 mins depending on the depth of information provided by respondents and if follow-up questions were needed. Most respondents answered questions pertaining to the main topics of discussion, with a small number of respondents providing minimal responses to climate-related questions depending on their knowledge and specialty (see Table 2).

Table 2. Responses to interview topics.

\begin{tabular}{lll}
\hline Interview Topics & $\begin{array}{l}\text { Detailed } \\
\text { Responses }\end{array}$ & $\begin{array}{l}\text { Minimal } \\
\text { Responses }\end{array}$ \\
\hline Climate & 59 & 6 \\
Environmental Change & 51 & 14 \\
Climate-Environment Impacts & 51 & 14 \\
Knowledge \& Support & 52 & 13 \\
\hline
\end{tabular}

\section{Results}

\subsection{LST and NDVI Maps}

LST and NDVI maps derived from the three Landsat images are displayed in Figure 2. LST data at the location of the Siem Reap station were $36.5^{\circ} \mathrm{C}$ on 7 January $1998,33.8^{\circ} \mathrm{C}$ on 21 January 2009 , and $35.2^{\circ} \mathrm{C}$ on 17 January 2019 . Maximum air temperatures observed at the station were $32.8^{\circ} \mathrm{C}$ on 7 January $1998,31.7^{\circ} \mathrm{C}$ on 21 January 2009 , and $33.2^{\circ} \mathrm{C}$ on 17 January $2019[52,53]$. The LST data are $\sim 2{ }^{\circ} \mathrm{C}$ higher than the air temperature maximums in 2009 and 2019; however, it is $3.7^{\circ} \mathrm{C}$ higher in 1998. The higher margin of error for 1998 may be due to inaccuracies with the LST data or due to the use of old weather 
equipment used in 1998, as the weather station was updated in the 2000s as per a key informant at the Ministry of Water Resources and Meteorology. As the Siem Reap weather station is located near the city, these maximum temperatures can only reflect temperatures close to and within the city. Much of the rural agricultural lowlands are estimated to observe higher temperatures, with Phnom Kulen National Park (PKNP) observing lower temperatures.

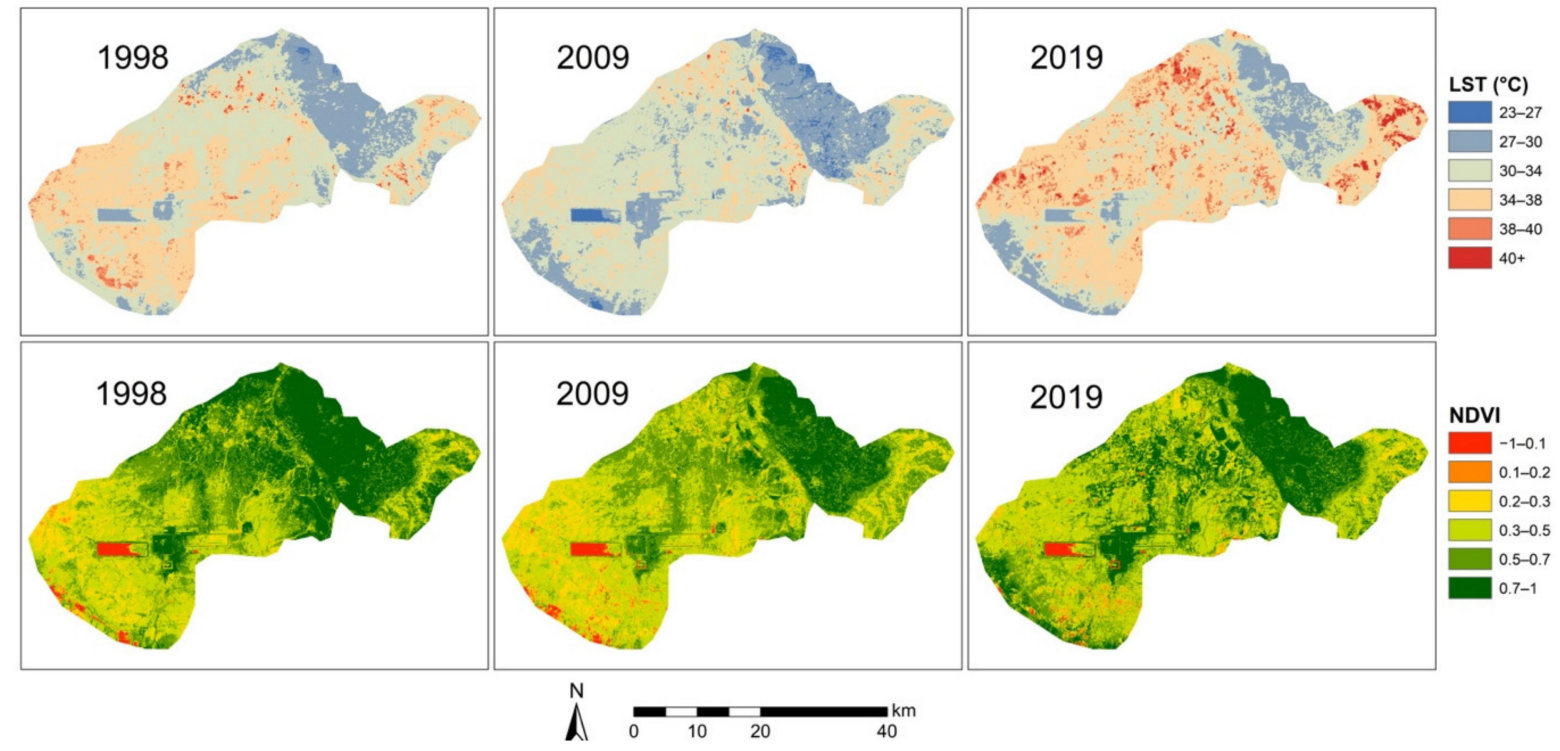

Figure 2. Results of land surface temperature (LST) and normalized difference vegetation index (NDVI) depicting spatial temperature and vegetation variation from 1998-2019.

Each LST map (Figure 2) represents the land surface temperature of when the image was taken. Temperatures in the LST maps between $23-27{ }^{\circ} \mathrm{C}$ (dark blue) and $27-30{ }^{\circ} \mathrm{C}$ (light blue) indicate cool to warm temperatures, followed by hotter temperatures between $30-34{ }^{\circ} \mathrm{C}$ (light green) and $34-38^{\circ} \mathrm{C}$ (peach), with temperatures of $38-40{ }^{\circ} \mathrm{C}$ (orange) and above $40^{\circ} \mathrm{C}$ (red) representing dramatically hotter temperatures. On 7 January 1998, the coolest temperatures feature most prominently in areas within PKNP, while higher temperatures are located throughout the rural agricultural lowlands (north, central, and south), as well as in areas around Siem Reap city. As noted by both LST values and air temperature, 21 January 2009, has milder temperatures throughout all three major areas. The coolest temperatures are still predominately located within areas of PKNP, while small areas with higher temperatures are located throughout areas of the rural agricultural lowlands close to PKNP. On 17 January 2019, the coolest temperatures are located within areas of PKNP, but to a much lesser degree, while the higher temperatures are located throughout much of the rural agricultural lowlands.

NDVI is divided into six categories, ranging from -1 to 1 , where low values of 0.2 or less represent no vegetation. Moderate values of $0.2-0.5$ represent sparse vegetation, and 0.5 and above represent dense vegetation. Like LST, NDVI represents vegetation conditions on the imaging data; however, it is also an indication of the climate condition for the particular season under study. In 1998, dense vegetation is observed in PKNP, throughout some areas in the rural agricultural lowlands, at the Angkor Archaeological Park (a few kilometers north of Siem Reap City), and in some areas around the city. Sparse vegetation is also observed throughout much of the rural agricultural lowlands and in the city. There are also areas of no vegetation (denuded dirt and concrete) scattered throughout the landscape, including the city. In 2009, dense vegetation decreases in PKNP throughout the rural agricultural lowlands and in the city as more sparse vegetation is observed. There has also been an increase in no vegetation observed in the city. In 2019, dense vegetation increases were observed in some areas in PKNP, with decreases in others. 
Several concentrated areas of dense vegetation growth in the rural agricultural lowlands, as well as in some small areas around the city is observed. Areas with little or no vegetation are also observed in the city.

Figure 3 displays three zoomed-in areas to show the relationships between LST and NDVI data: (a) rural mountain (PKNP), (b) rural agricultural lowlands, and (c) urban (Siem Reap City). Overall, areas with significant human intervention (agriculture, plantation forests, urbanization), as seen in the NDVI maps, displayed higher temperatures in the LST maps. In PKNP (Figure 3a), the zoomed-in NDVI showed more light green patches in 2009 and 2019 NDVI maps, suggesting the landscape has become fragmented on PKNP, where large-scale deforestation and conversion from slash and burn farming to cashew nut plantation have occurred over the years [54]. Despite the growth of plantation forests (cashew nut trees) in some areas that showed a recovery of NDVI values from 2009 to 2019 (i.e., fewer light green patches in the 2019 NDVI map), the LST maps still noted a general higher surface temperature in 2019.

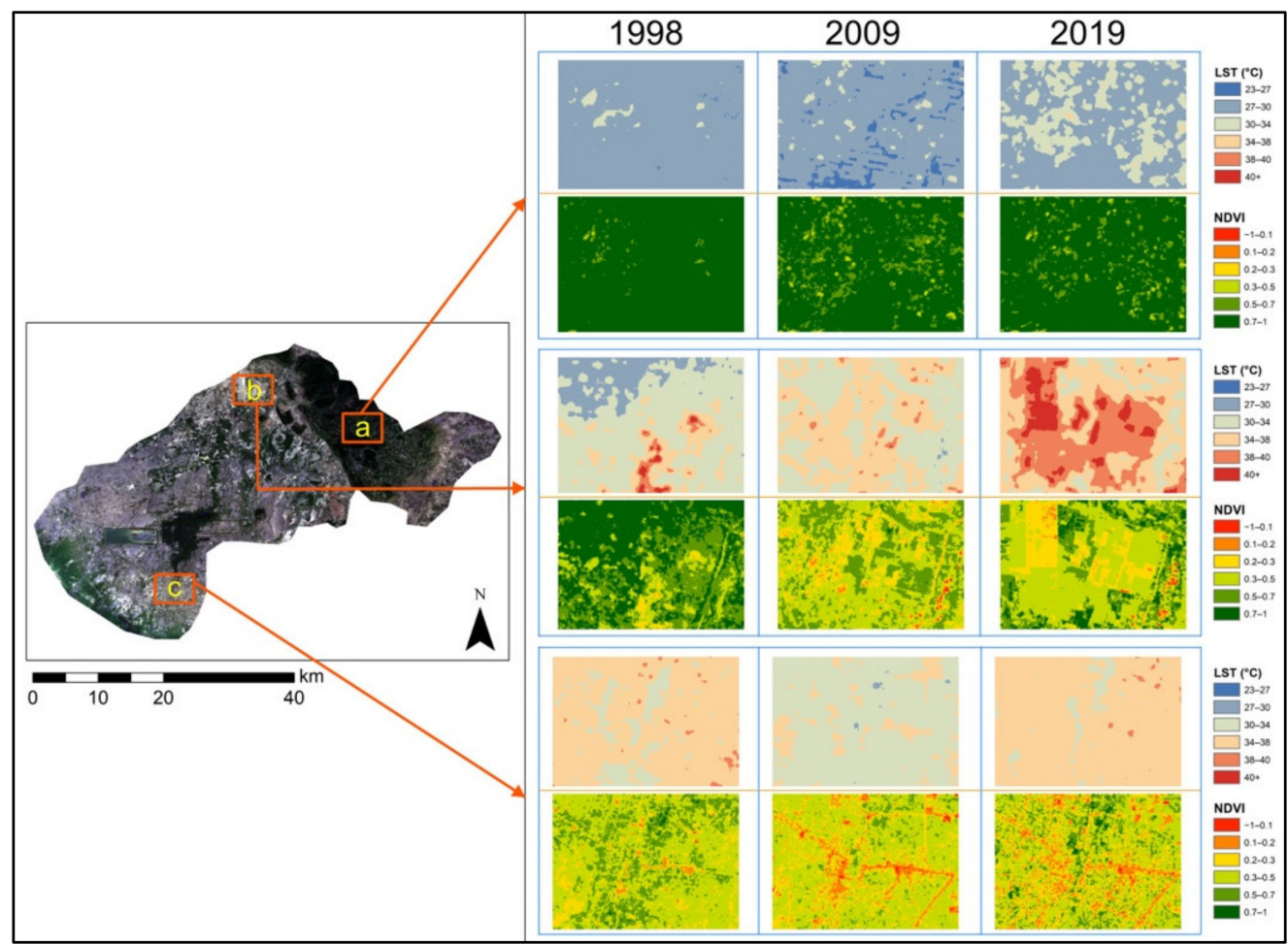

Figure 3. Zoomed in areas to show detailed LST and NDVI data. (a) rural mountains, (b) rural agricultural lowlands, and (c) urban area.

The decreasing NDVI values (from dominant dark green in 1998 to light green and yellow in 2019) in the rural agricultural lowlands (Figure 3b) demonstrated that agricultural expansion has proceeded at a high rate, where between $80-90 \%$ of people that live in these areas are involved in agricultural production [55]. Correspondingly, in these rural agricultural lowlands, the flat, cleared land produced high exposure to extreme heat, as seen in the LST maps. Siem Reap City (Figure 3c) exhibited both expansions of impervious areas as well as some greening (i.e., high NDVI values), especially leading up to the Angkor Archaeological Park and along the Siem Reap River (see Figure 4). Despite urban expansion from 1998 to 2009, the LST did not display higher surface temperatures in 2009, while similar surface temperature values in the city are exhibited in 1998 and 2019. 


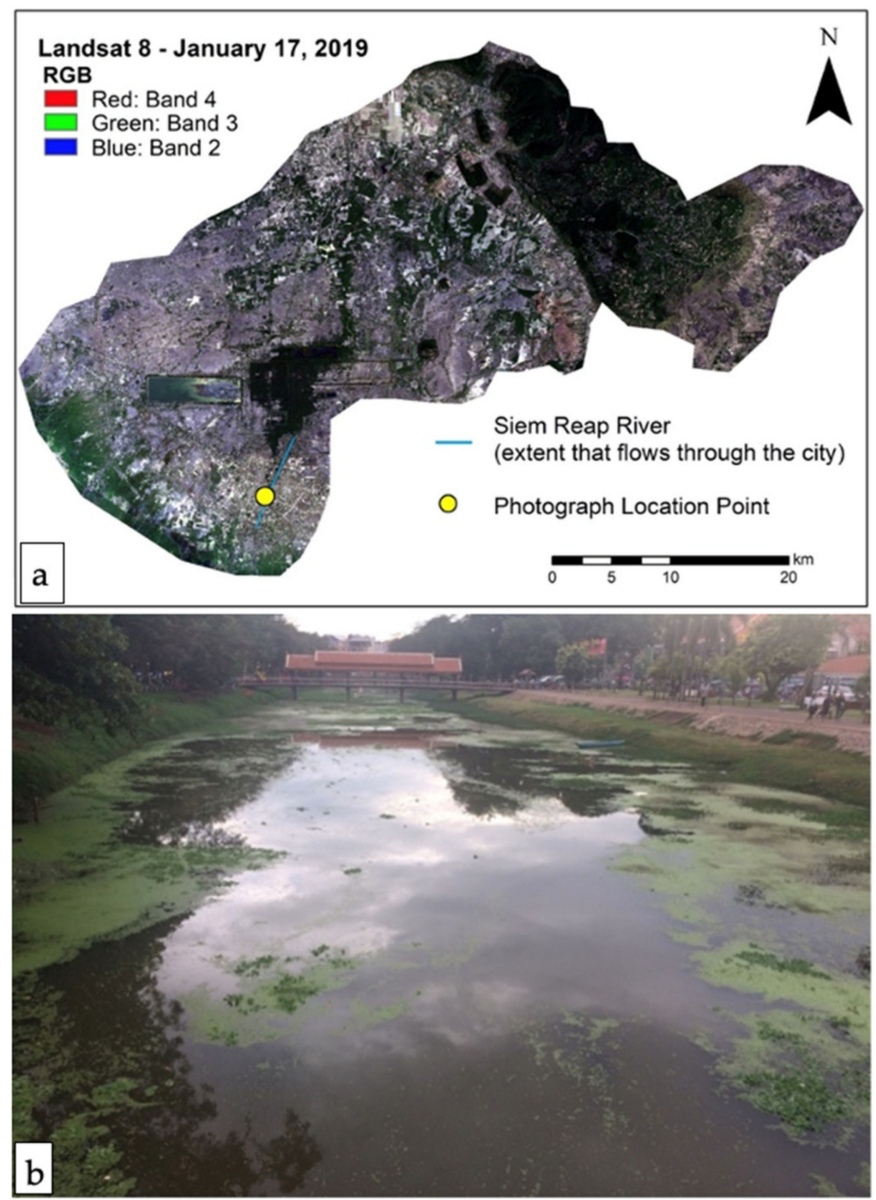

Figure 4. (a) Greater Angkor Region depicting the extent of the Siem Reap River in the city and the location of photograph $4 \mathrm{~b}$ on the map (b) A photograph of the Siem Reap River in Siem Reap City.

LST-NDVI regressions were performed to quantitatively examine LST-NDVI relationships (Figure 5). All three graphs displayed significantly strong relationships between temperature (i.e., LST) and green vegetation (i.e., NDVI) in the study area, with NDVI explaining $76.3 \%$ of spatial temperature in $1998,65.9 \%$ in 2009 , and $66.6 \%$ in 2019 . The slope of the regressions suggests that every 0.1 decrease in NDVI values leads to around 1.0 increase in temperature (i.e., 1.21 in 1998, 0.94 in 2009, and 0.98 in 2019). Spatially, temperatures range from $26^{\circ} \mathrm{C}$ to $41^{\circ} \mathrm{C}$ in all three years, with areas showing higher vegetation cover correspondingly having lower temperature values. The highest LST observed is in seasonal agriculture at $40.6^{\circ} \mathrm{C}$ in 2019 , and the lowest temperature is in densely vegetated areas at $26.6^{\circ} \mathrm{C}$ in 2009 . Specifically, densely vegetated areas exhibited the lowest mean temperatures at $30.5^{\circ} \mathrm{C}$ in $1998,29.2^{\circ} \mathrm{C}$ in 2009 , and $31.2^{\circ} \mathrm{C}$ in 2019 . These corresponded with NDVI values of 0.6 and above, which is representative of dense vegetation. Sparsely vegetated areas observed slightly higher temperatures with mean temperatures of $34.8^{\circ} \mathrm{C}$ in $1998,32.5^{\circ} \mathrm{C}$ in 2009 , and $34.9^{\circ} \mathrm{C}$ in 2019 , and a mean NDVI around 0.5. Seasonal agricultural and impervious areas exhibited the highest temperatures and the lowest NDVI values. Mean temperatures for seasonal agriculture are $36.0^{\circ} \mathrm{C}$ in $1998,34.1^{\circ} \mathrm{C}$ in 2009 , and $36.8^{\circ} \mathrm{C}$ in 2019 , while impervious areas have mean temperatures of $36.0^{\circ} \mathrm{C}$ in 1998 , $33.7^{\circ} \mathrm{C}$ in 2009 , and $36.6^{\circ} \mathrm{C}$ in 2019 . Impervious areas with less vegetation observed a mean NDVI of 0.2 , and seasonal agriculture that occupies most of the study area had a mean NDVI of around 0.3. Temporally, the graphs also indicated areas of high vegetation cover are shifting, with a mean NDVI of 0.74 in 1998, decreasing to 0.68 in 2009, and increasing to 0.77 in 2019. Additional analysis for study years $(1997,2001,2007,2011,2018,2020)$ was performed to validate these findings. 


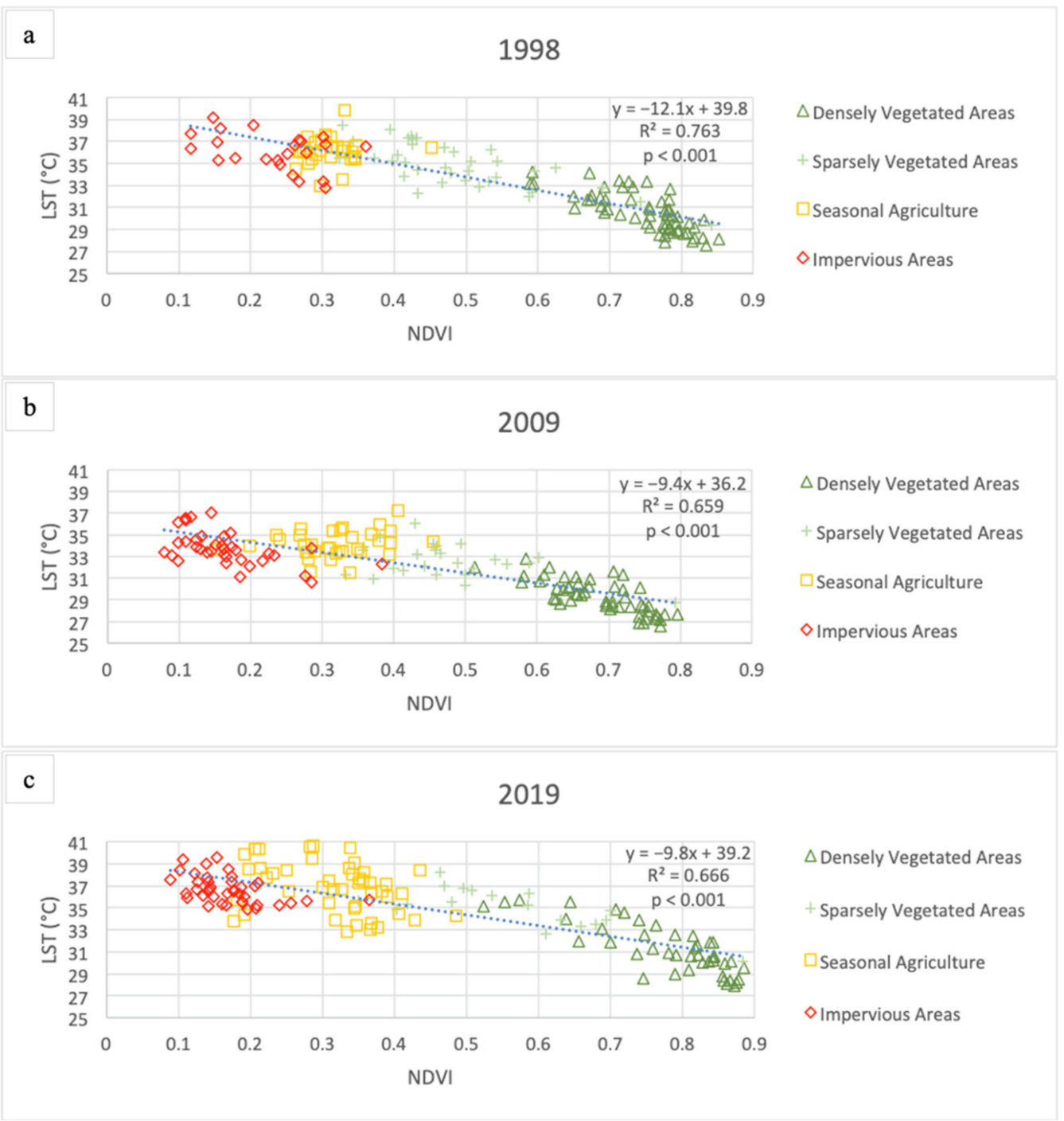

Figure 5. LST-NDVI linear regressions. (a) 1998 linear regression, (b) 2009 linear regression, and (c) 2019 linear regression.

\subsection{People and Temperature Dynamics}

A word frequency query in NVivo (QSR International, Melbourne, Australia) revealed that when talking about temperature, respondents most frequently spoke of water, forest, hotter, change, people, climate, last, and rain. Secondary topics included decreased, season, wind, farming, decline, environment, and problem. The overlap of temperature with landscape variables is particularly significant, as it suggests that local perceptions of temperature are linked with the environment and natural resources.

In the PKNP area, respondents identified notable change in temperature. They stated that the temperature is hotter now than before. Some observed a change from around 2015-2016 while, for others, significant temperature changes have only been noticeable from 2017-2018. While most respondents in PKNP identified hotter temperatures over the years with 2019 being very hot, several respondents discussed more a fluctuation of hotter temperatures, noting that hotter temperatures are evident in the last 5 years (2015-2019) but the years for which they identified the hottest temperatures differ. Respondents explained that despite perceiving a rise in temperature, it is still cooler on PKNP than in the lowlands, when they visit these areas. For example, one respondent stated that despite the higher temperatures, he still preferred to live in PKNP because it remains cooler in comparison to other areas, while another respondent indicated when he is in Siem Reap City, 
the high temperatures drain his energy, but when he is in PKNP he feels energized by the cooler temperatures.

I like to live here because it is easy to breathe, and the weather is good. I can sleep very well at night, and I have energy when I get up in the morning. If I sleep at the lower area, I have no energy. I don't know how to live there.

People living in the rural agricultural lowlands responded similarly, where most respondents commented on how much hotter it has been in recent years. The year 2019 is identified as a very hot year in comparison to the previous year. One respondent stated that it has been getting hotter over the years, and he singled out 2019 as a very hot year. Changes in temperature are identified in the mid-to-late 2000s, where before 2008, the temperature is perceived to be cooler, but in the last ten years, the temperature has undergone significant notable changes. One respondent commented that with the current temperature, it is very hard to live now. His livestock is dying, his crop yields are decreased, and there is less rainfall.

The crop yield last year (2018) was better than this year (2019). The temperature is much hotter, and the animals died because they don't have enough water to drink.

Another respondent stated that the temperature now is too hot, and he would prefer to live in the previous situation where the temperature is milder.

Respondents in the city also observed hotter temperatures, noting that "it is hotter than other years." A key informant stated that the year 2019 was very hot, especially in the city, but made more direct connections on the impacts of high temperatures to people in rural areas. Similarity, in the city, respondents primarily noted hotter temperatures but did not discuss major disruptions to daily life.

\subsection{Climate-Land Interactions}

Perceptions of local temperature changes are strongly associated with environmental variables. Most respondents expressed the view that changes in temperature are a result of landscape changes. In PKNP, the degraded ecosystem was discussed at length, where the most prominent environmental variables identified were water and forests. Primary and secondary forests being replaced with cashew nut plantations is the key reason respondents provided for hotter temperatures and lower water levels. A study conducted by Trabucco et al. [56] noted that plantation forests may have considerable impacts on water resources and, an example from Sumatra, revealed that oil palm plantations displayed warmer temperatures than forests [57]. A major point of contention among residents was the impact these changes have had on farming, the main livelihood activity for people in PKNP.

It is because we lost the forests. The climate is changed, and the water is decreased because of what has happened with the forests.

Although many of the areas where water spring points are located are now protected, water concerns and hotter days were discussed by residents. Additionally, the conversion of natural forests to cashew nut plantations was also noted as a problem for developing PKNP for ecotourism, as tourists want to see nature, not plantations. For people in PKNP, temperature changes may result from the sharp contrast of once having forests that shaded and reduced the amount of heat reaching the ground to now having more direct contact with high temperatures.

Respondents in the rural agricultural lowlands discussed water most often in relation to temperature and associated changes in temperature with the loss of forests. Loss of forests can have severe impacts on the evapotranspiration process and groundwater cycle [58]. According to the respondents, the temperature started to change when people began clearing more land for farming. Respondents connected irregular rainfall patterns, dying animals, and dried out crop yields from heat stress to high temperatures and low water levels. In 2019, many farmers were advised to plant two times instead of three times 
and choose 3-month drought-tolerate crops instead of 6-month crops. For many families, agricultural activities in general seem to be less in 2019 because of less water. Even in the areas where access to stored reservoir water was available for farming, respondents noted lower water levels in the canals.

This year we have less rain and less water in the canals meaning we have less water to use for the rice farms.

In most cases, temperature changes were expressed in relation to farming, as sensitivity to heat in agricultural lowlands is amplified by direct exposure in open agricultural landscapes. Additionally, the difference in resource access and social services in these landscapes is also important to consider.

Respondents in the city also expressed the view that temperatures are getting hotter, and this may result from environmental changes, but speak about fewer direct impacts. As Siem Reap is a small, urbanizing city, it does not yet feature the high proportion of hard surfaces typically seen in other cities, such as tall skyscrapers and elaborate roadways. Typically, cities do exhibit higher temperatures than surrounding areas, as conveyed by Bounoua et al. [7] where several U.S. cities demonstrated this phenomenon, except for Phoenix, where the city was greener than surrounding areas. Close proximity to the Tonle Sap (the largest freshwater lake in Southeast Asia), may also help to regulate temperatures in the city. For many, outdoor activities involved a fair degree of shade, indoor activities often used fans or air conditioning, and easy access to amenities typically described a different relationship for urban residents with temperature compared to individuals that are more directly exposed to the elements.

\section{Discussion}

\subsection{Interpreting Spatial Temperature}

The strong relationship between temperature and land expressed both in the remote sensing results and the interview analysis revealed that land transitions to plantation forests, agricultural land, and urban areas have contributed to temperature changes in this area. This has raised concerns where degraded ecosystems and hotter temperatures have led to disruptions in livelihood activities.

The LST-NDVI results, air temperature, and perception data showed some consistency and inconsistency with the degree of correlation among the datasets. While LST data in 2019 are the highest, these temperatures are marginally higher than in 1998, with 2009 having the lowest temperatures. 2019 having the highest temperatures does correspond to perception data that identified hotter temperatures especially in the last 5-10 years. At the Siem Reap Station, the LST data range from $33.9^{\circ} \mathrm{C}$ to $36.5^{\circ} \mathrm{C}$ with the highest temperature in 1998 just marginally greater than in 2019, while the air temperature data ranges from $31.7{ }^{\circ} \mathrm{C}$ to $33.2^{\circ} \mathrm{C}$ with the highest temperature in 2019. These temperatures exhibited some fluctuation but did not show a consistent increase. A reduction of green vegetation from 1998 to 2009 is clearly observed in NDVI data and noticed by respondents from the interviews. Despite 2009 having an overall lower temperature than 1998 and 2019, areas with less vegetation still observed higher temperatures. Greening (a recovery of high NDVI values) are observed in the NDVI findings from 2009-2019 throughout the region. In PKNP, despite greening, temperatures are overall higher. In the rural agricultural lowlands, areas with greening exhibited lower temperatures, while areas with less vegetation observed higher temperatures, and in the city, despite urban expansion and greening, temperatures are similar to the 1998 values. Findings also indicated that a 0.1 reduction in NDVI leads to an average $1.0^{\circ} \mathrm{C}$ increase in temperature for the study area. This is valuable for decision makers and planners because it provides clear evidence towards the importance of naturally forested areas for temperature regulation.

\subsection{Mobilizing Climate Resilience Action}

There is a wide range of experiences surrounding climate action across the region. Interviews with residents and key informants provided firsthand experience on how climate 
awareness manifested across the region and the capacity to which it operated, offering new insights for future climate planning.

One of the main climate actions within the Greater Angkor Region is tree planting, which is being done by both the public and private sectors. The Provincial Department of Agriculture, Forestry \& Fisheries (PDAFF) stated that to mitigate climate concerns, they provide hundreds of thousands of tree saplings to schools for replanting every year. An entrepreneur in the city explained that he and a few of his colleagues are trying to do what they can for the environment. They set up a tree nursery where they grow thousands of trees and when the trees are big enough, they will give them away to public places like schools and hospitals to be transplanted. Additionally, designated areas for communityprotected forest areas and the expansion of these have become more critical for forest conservation within this region.

Climate resilience action, however, has not manifested the same across the region for everyone. In PKNP, more awareness, support, and engagement surround climate as the Ministry of Environment and multiple NGOs play a large role. Generally, most residents had a moderate degree of understanding towards changes in temperature, noting higher temperatures, irregular rainfall patterns, and the capacity to explain impacts on their livelihood activities. A key informant added that, particularly in this area, additional support for raising awareness is needed, especially in terms of more sustainable agriculture practices and more livelihood options. One resident noted that besides what the government is doing, he is not clear on what else his village can do. As noted by residents in PKNP, more training and education need to be provided on what people can do so climate action is more proactive and less reactive (i.e., reducing harvests).

In the rural agricultural lowlands, climate resilience action is variable depending on the support and engagement they receive from local government units and the inclusion of NGOs working on climate related projects. For some, there is an awareness of changes in temperature, especially with the support of NGOs that provide workshops and community outreach, but adaptation is a slow process. One respondent noted that changes in temperature have made things very difficult for him, but he does not know what can be done to mitigate the problems. Other respondents identified lower degrees of awareness, stating they do not know much about climate change. They notice something is changing, but they do not know how to adapt to it. Many were also unsure about what supports are available to them. Several key informants urged for an increase in social awareness through community engagement and social media announcements to help improve climate resilience action. Informants at both national and provincial levels stated that not enough money was available for full implementation and noted financial and technical supports from NGOs are important. However, a key informant added that in terms of long-term sustainability and adaptation, once projects are completed, they receive minimal support and follow-up, which makes them hard to sustain.

Climate awareness in the city was moderate based on the key informants and residents we spoke to. The Provincial Department of Agriculture, Forestry \& Fisheries (PDAFF) explained that it is difficult to designate and maintain community urban forest spaces. The Strategic Program for Climate Resilience also noted that at the time Siem Reap City was not a target project for them in terms of mainstreaming climate resilience. However, the Global Green Growth Institute stated that additional projects focusing on secondary cities such as Siem Reap were being developed.

\subsection{Consistency and Limitations}

This study showed a degree of consistency and inconsistency in relation to quantitative and qualitative temperature analysis. Although continual temperature increase could not be verified in this study, a strong relationship between temperature and ground features was consistent among the LST and interview results. Limitations of this study were mainly due to a lack of in situ climate data from additional weather stations in the area. Weather stations and measurement system updates in the area posed a restriction to map or validate 
the temperature maps throughout the 20 years, as these data would improve accuracy in measuring ground temperatures for PKNP and the rural agricultural lowlands. As no cloud free Landsat images were available for the study years $(1998,2009,2019)$ during the wet season within the study site boundary, a seasonal comparison could not be performed for this study. Future climate studies for this region would benefit from seasonal comparison to denote seasonal change in temperature. This study, however, made every effort to use different datasets (LST, meteorology, interviews) to accurately portray temperature in this area with the chosen methods.

\section{Conclusions}

The findings of this research are important because they highlight temperature change in this region, provide a deeper understanding of its impacts, and offer new insights into how climate resilience action is occurring in different land types. The results indicated that changes in temperature were most prominent in PKNP and the rural agricultural lowlands where residents noted the highest degrees of concern for how temperature change is impacting livelihood activities. The temperature was strongly related to ground features: the high temperatures were in areas with little to no vegetation, while low temperatures were observed in areas with dense vegetation. While tree planting and forest conservation initiatives are already underway as climate resilience strategies, awareness, and the capacity to adapt to temperature change remain uneven across the landscape, calling for stronger engagement, education, and training.

The use of mixed methods, specifically remote sensing and interviews was beneficial to this study because combined, it provided clear indication towards the areas where temperature is most severe and the corresponding impacts on ecosystem and human wellbeing, which is valuable for climate resilience planning. In using this approach, the main research questions have been addressed in terms of how and why temperature is changing, if people are able to adapt and enact climate resilience strategies and what recommendations are needed for improving climate action. First, as noted in the linear regression, one of the main factors influencing temperature is the change in vegetation. This was corroborated with the interview data, where most respondents connected temperature with landscape features. Second, the ability to enact climate resilience strategies was uneven across the landscape, depending on the level of engagement with authorities and NGOs in the area. While awareness may be improving in some areas, action remains slow and largely reactive. Third, recommendations provided by respondents called for more engagement, training, and education on climate action to increase understanding and awareness of changing temperature dynamics and prepare residents for the future.

The broader implications of this study demonstrate the applicably of integrated methods to demonstrate the urgent need to address changing climate dynamics. First, this study highlighted the different realities that residents in different land types (rural and urban) face in responding to climate change. Livelihood activities and geographic location were two determinants within this study which are also applicable across the globe. Second, this study demonstrated the connection between vegetation and temperature within the study area, which has been reported in other studies, affirming the importance of natural forests and the need to increase efforts to maintain and protect them. Third, the study emphasized challenges with climate resilience action and awareness within the study area, which is applicable to many areas across the world, where not enough resources, funding, and education are available.

Author Contributions: Conceptualization, L.M. and Y.H.; methodology, L.M.; software, L.M.; validation, L.M.; formal analysis, L.M.; investigation, L.M. and Y.H.; resources, L.M. and Y.H.; data curation, L.M.; writing —original draft preparation, L.M.; writing—review and editing, L.M. and Y.H.; visualization, L.M.; supervision, Y.H.; project administration, Y.H.; funding acquisition, L.M. and Y.H. All authors have read and agreed to the published version of the manuscript. 
Funding: This research was supported by the SSHRC Insight Grant: 435-2012-0638, and the IPaSS Grant from IDRC: 107776-001 and SSHRC: 895-2013-3004. It was also supported by the Natural Sciences and Engineering Research Council of Canada (NSERC) through the NSERC Discovery Program (RGPIN-386183) awarded to Yuhong He. This work was also financially supported by the School of Graduate Studies at the University of Toronto, the Department of Geography, Geomatics and Environment at University of Toronto Mississauga, and the Mitacs Research Training Award awarded to Leah Marajh.

Institutional Review Board Statement: The study was conducted in accordance with the University of Toronto Research Ethics Board (protocol 00037308 approved on 19 March 2019).

Informed Consent Statement: Informed consent was obtained from all subjects involved in the study.

Data Availability Statement: Not applicable.

Acknowledgments: We thank the Ministry of Water Resources and Meteorology in Cambodia, the Ministry of Environment in Cambodia, the Siem Reap Provincial Administration, the Siem Reap Provincial Department of Water Resources and Meteorology, the Archaeology and Development Foundation in Siem Reap, and the Cambodian Archaeological Lidar Initiative in Siem Reap. We also thank Amrita Daniere for her support through the project and Mitchell T. Bonney for help with remote sensing image processing. A special thanks to the late Lisa Welch Drummond.

Conflicts of Interest: The authors declare no conflict of interest. The funders had no role in the design of the study; in the collection, analyses, or interpretation of data; in the writing of the manuscript, or in the decision to publish the results.

\section{References}

1. IPCC. Managing Risks of Extreme Events and Disasters to Advance Climate Change Adaptation. A Special Report of Working Groups I and II of the Intergovernmental Panel on Climate Change; Field, C.B., Barros, V., Stocker, T.F., Qin, D., Dokken, D.J., Ebi, K.L., Mastrandrea, M.D., Mach, K.J., Plattner, G.-K., Allen, S.K., et al., Eds.; Cambridge University Press: Cambridge, UK; New York, NY, USA, 2012.

2. IPCC. Climate Change and Land: An IPCC Special Report on Climate Change, Desertification, Land Degradation, Sustainable land Management, Food Security, and Greenhouse Gas Fluxes in Terrestrial Ecosystems; Shukla, P.R., Skea, J., Calvo Buendia, E., Masson-Delmotte, V., Pörtner, H.-O., Roberts, D.C., Zhai, P., Slade, R., Connors, S., van Diemen, R., et al., Eds.; IPCC: Geneva, Switzerland, 2019; In press.

3. Hansen, J.; Sato, M.; Ruedy, R. Perception of climate change. Proc. Natl. Acad. Sci. USA 2012, 109, E2415-E2423. [CrossRef] [PubMed]

4. Hijioka, Y.; Lin, E.; Pereira, J.J.; Corlett, R.T.; Cui, X.; Insarov, G.E.; Lasco, R.D.; Lindren, E.; Surjan, A.A. Climate Change 2014: Impacts, Adaptation, and Vulnerability. Part B: Regional Aspects Contribution of Working Group II to the Fifth Assessment Report of the Intergovernmental Panel on Climate Change; Barros, V.R., Field, C.B., Dokken, D.J., Mastrandrea, M.D., Mach, K.J., Bilir, T.E., Chatterjee, M., Ebi, K.L., Estrada, Y.O., Genova, R.C., et al., Eds.; Cambridge University Press: Cambridge, UK; New York, NY, USA, 2014; pp. 1327-1370.

5. Loza, A.R.A.; Fidélis, T. Literature review on the analysis of climate change risks in the environmental impact assessment of dams. Impact Assess. Proj. Apprais. 2021, 39, 277-289. [CrossRef]

6. Schlenker, W.; Lobell, D.B. Robust negative impacts of climate change on African agriculture. Environ. Res. Lett. 2010, 5, 014010. [CrossRef]

7. Bounoua, L.; Zhang, P.; Mostovoy, G.; Thome, K.; Masek, J.; Imhoff, M.; Shepherd, M.; Quattrochi, D.; Santanello, J.; Silva, J.; et al. Impact of urbanization on US surface climate. Environ. Res. Lett. 2015, 10, 084010. [CrossRef]

8. Wolff, N.H.; Masuda, Y.J.; Meijaard, E.; Wells, J.A.; Game, E.T. Impacts of tropical deforestation on local temperature and human well-being perceptions. Glob. Environ. Change 2018, 52, 181-189. [CrossRef]

9. ADB. The Economics of Climate Change in Southeast Asia: A Regional Review; Asian Development Bank: Manila, Philippines, 2009.

10. FAO. The State of Food and Agriculture: Climate Change Agriculture and Food Security; Food and Agriculture Organization of the United Nations: Rome, Italy, 2016.

11. National Research Council. Our Common Journey: A Transition Toward Sustainability; The National Academies Press: Washington DC, USA, 1999.

12. Gunderson, L.H.; Holling, C.S. Panarchy: Understanding Transformations in Human and Natural Systems; Island Press: Washington, DC, USA, 2002.

13. Dearing, J.A. Human-Environment Interactions: Learning from the Past. In Sustainability or Collapse: An Integrated History and Future of People on Earth; Constanza, R., Graumlich, L.J., Steffen, W., Eds.; The MIT Press: Cambridge, MA, USA, 2007; pp. 19-37. 
14. Howe, P.D.; Markowitz, E.M.; Lee, T.M.; Ko, C.-Y.; Leiserowitz, A. Global perceptions of local temperature change. Nat. Clim. Chang. 2012, 3, 352-356. [CrossRef]

15. Guo, J.; Ren, H.; Zheng, Y.; Lu, S.; Dong, J. Evaluation of Land Surface Temperature Retrieval from Landsat 8/TIRS Images before and after Stray Light Correction Using the SURFRAD Dataset. Remote Sens. 2020, 12, 1023. [CrossRef]

16. Sekertekin, A.; Bonafoni, S. Land Surface Temperature Retrieval form Landsat 5,7, and 8 over Rural Areas: Assessment of Different Retrieval Algorithms and Emissivity Models and Toolbox Implementation. Remote Sens. 2020, 12, 294. [CrossRef]

17. Williamson, S.N.; Hik, D.S.; Gamon, J.A.; Kavanaugh, J.L.; Flowers, G.E. Estimating Temperature Fields from MODIS Land Surface Temperature and Air Temperature Observations in a Sub-Arctic Alpine Environment. Remote Sens. 2014, 6, 946-963. [CrossRef]

18. Hulley, G.C.; Ghent, D.; Gottsche, F.M.; Guillevic, P.C.; Mildrexler, D.J.; Coll, C. Land Surface Temperature. In Taking the Temperature of the Earth: Steps Towards Integrated Understanding of Variability and Change; Hulley, G.C., Ghent, D., Eds.; Elsevier: Amsterdam, The Netherlands, 2019; pp. 57-127.

19. Pitman, A.J.; Avila, F.B.; Abramowitz, G.; Wang, Y.P.; Phipps, S.J.; de Noblet-Ducoudre, N. Importance of background climate in determining impact of land-cover change on regional climate. Nat. Clim. Change 2011, 1, 472-475. [CrossRef]

20. Das, N.; Mondal, P.; Sutradhar, S.; Ghosh, R. Assessment of variation of land use/land cover and its impact on land surface temperature of Asansol subdivision. Egypt. J. Remote Sens. Space Sci. 2021, 24, 131-149. [CrossRef]

21. Gohain, K.J.; Mohammad, P.; Goswami, A. Assessing the impact of land use land cover changes on land surface temperature over Pune city, India. Quat. Int. 2021, 575-576, 259-269. [CrossRef]

22. Al Kafy, A.; Faisal, A.-A.; Rakib, A.A.; Fattah, M.d.A.; Rahaman, Z.A.; Sattar, G.S. Impact of vegetation cover loss on surface temperature and carbon emission in a fastest-growing city, Cumilla, Bangladesh. Build. Environ. 2022, 208, 108573. [CrossRef]

23. Reyes-Garcia, V.; Fernandez-Llamazares, A.; Gueze, M.; Garces, A.; Mallo, M.; Vila-Gomez, M.; Vilaseca, M. Local indicators of climate change: The potential contribution of local knowledge to climate research. WIREs Clim. Chang. 2016, 7 , 109-124. [CrossRef] [PubMed]

24. Denton, F.; Wilbanks, T.J.; Abeysinghe, A.C.; Burton, I.; Gao, Q.; Lemos, M.C.; Masui, T.; O’Brien, K.L.; Warner, K. Climate-resilient pathways: Adaptation, mitigations, and sustainable development. In Climate Change 2014: Impacts, Adaptation, and Vulnerability. Part A: Global Sectoral Aspects. Contribution of Working Group II to the Fifth Assessment Report of the Intergovernmental Panel on Climate Change; Field, C.B., Barros, V.R., Dokken, D.J., Mach, K.J., Mastrandrea, M.D., Bilir, T.E., Chatterjee, M., Ebi, K.L., Estrada, Y.O., Genova, R.C., et al., Eds.; Cambridge University Press: Cambridge, UK; New York, NY, USA, 2014; pp. 1101-1131.

25. Berkes, F. Understanding Uncertainty and Reducing Vulnerability: Lessons from Resilience Thinking. Nat. Hazards 2007, 41, 283-295. [CrossRef]

26. Holling, C.S. Understanding the Complexity of Economic, Ecological, and Social Systems. Ecosystems 2001, 4, 390-405. [CrossRef]

27. Walker, B.; Salt, D. Resilience Thinking; Island Press: Washington, DC, USA, 2006.

28. Tyler, S.; Moench, M. A framework for urban climate resilience. Clim. Dev. 2012, 4, 311-326. [CrossRef]

29. Mikulewicz, M. Thwarting adaptation's potential? A critique of resilience and climate-resilient development. Geoforum 2019, 104, 267-282.

30. Prakash, A. Boiling Point. Financ. Dev. 2018, 55, 22-26.

31. Sok, C.; Choup, S. Climate change and groundwater resources in Cambodia. J. Groundw. Sci. Eng. 2017, 5, 31-34.

32. GSSD. National Adaptation Plan Process in Cambodia; General Secretariat of National Council for Sustainable Development/Ministry of Environment: Phnom Penh, Cambodia, 2017.

33. National Climate Change Committee. Cambodia Climate Change Stategic Plan 2014-2023; National Climate Change Committee: Phnom Penh, Cambodia, 2013.

34. Chim, K.; Tunnicliffe, J.; Shamseldin, A.; Chan, K. Identifying future climate change and drought detection using CanESM2 in the upper Siem Reap River, Cambodia. Dyn. Atmos. Ocean. 2021, 94, 101182. [CrossRef]

35. Chim, K.; Tunnicliffe Shamseldin, A.; Bun, H. Assessment of land use and climate change effects on hydrology in the upper Siem Reap River and Angkor Temple Complex, Cambodia. Environ. Dev. 2021, 39, 100615. [CrossRef]

36. Perur, S. What the Collapse of Ancient Capitals Can Teach Us about the Cities of Today. The Guardian. 2015. Available online: https://www.theguardian.com/cities/2015/jan/14/what-the-collapse-of-ancient-capitals-can-teach-us-about-the-citiesof-today (accessed on 12 May 2017).

37. Lovgren, S. Angkor Wat's Collapse from Climate Change has Lessons for Today. National Geographic. 2017. Available online: https:/ / www.nationalgeographic.com/science/article/angkor-wat-civilization-collapsed-floods-drought-climate-change (accessed on 12 May 2017).

38. Fletcher, R.; Buckey, B.M.; Pottier, C.; Wang, S.-Y.S. Fourteenth to Sixteenth Centuries AD: The Case of Angkor and Monsoon Extremes in Mainland Southeast Asia. In Megadrought and Collapse: From Early Agriculture to Angkor; Weiss, H., Ed.; Oxford University Press: New York, NY, USA, 2017; pp. 275-314.

39. Lieberman, V.; Buckley, B. The Impact of Climate on Southeast Asia, circa 950-1820: New Findings. Mod. Asian Stud. 2012, 46, 1049-1096. [CrossRef]

40. Buckley, B.M.; Fletcher, R.; Wang, S.-Y.S.; Zottoli, B.; Pottier, C. Monsoon extremes and society over the past millennium on mainland Southeast Asia. Quat. Sci. Rev. 2014, 95, 1-19. [CrossRef]

41. Acker, R. New Geographical Tests of the Hydraulic Thesis at Angkor. S. E. Asia Res. 1998, 6, 5-47. [CrossRef] 
42. Evans, D.; Pottier, C.; Fletcher, R.; Hensley, S.; Tapley, I.; Milne, A.; Barbetti, M. A Comprehensive Archaeological Map of the World's Largest Preindustrial Settlement Complex at Angkor, Cambodia. Proc. Natl. Acad. Sci. USA 2007, 104, 14277-14282. [CrossRef]

43. Heikkila, E.J.; Peycam, P. Economic Development in the Shadow of Angkor Wat: Meaning, Legitimation, and Myth. J. Plan. Educ. Res. 2010, 29, 294-309. [CrossRef]

44. Esposito, A. Planning Urban Development from an Outsider's Perspective: Siem Reap, the Backdrop of Changing Urban Representations. Antropologia 2014, 1, 143-154.

45. Penny, D.; Chevance, J.B.; Tang, D.; De Greef, S. The Environmental Impact of Cambodia's Ancient City of Mehendraparvata (Phnom Kulen). PLoS ONE 2014, 9, e84252.

46. Chevance, J.B.; Evans, D.; Hofer, N.; Sakhoeun, S.; Chhean, R. Mahendraparvata: An early Angkor-period capital defined through airborne laser scanning at Phnom Kulen. Antiquity 2019, 93, 1303-1321. [CrossRef]

47. UNDP. Restoring Landscape in Steung Siem Reap Watershed Area; Country Landscape Program Strategy: Phnom Penh, Cambodia, 2012.

48. Kummu, M. Water Management in Angkor: Human Impacts on Hydrology and Sediment Transportation. J. Environ. Manag. 2009, 90, 1413-1421. [CrossRef] [PubMed]

49. Gaughan, A.E.; Binford, M.W.; Southwort, J. Tourism, Forest Conversion, and Land Transformations in the Angkor Basin, Cambodia. Appl. Geogr. 2009, 29, 212-223. [CrossRef]

50. Ermida, S.L.; Soares, P.; Manta, V.; Gottsche, F.-M.; Trigo, I.F. Google Earth Engine Open-Source Code for Land Surface Temperature Estimation from the Landsat Series. Remote Sens. 2020, 12, 1471. [CrossRef]

51. Sobrino, J.A.; Jimenez-Munoz, J.C.; Paolini, L. Land surface temperature retrieval from Landsat TM 5. Remote Sens. Environ. 2004, 90, 434-440. [CrossRef]

52. Ministry of Water Resources and Meteorology. Climate Data for Siem Reap Weather Station; Ministry of Water Resources and Meteorology: Phnom Penh, Cambodia, 2019.

53. Siem Reap Provincial Department of Water Resources and Meteorology. Climate Data for Siem Reap Weather Station; Siem Reap Provincial Department of Water Resources and Meteorology: Siem Reap, Cambodia, 2019.

54. Ministry of Environment. Management Programme Kulen Mountain National Park 2018-2027; General Directorate of Administration for Nature Conservation and Protection, the Ministry of Environment: Phnom Penh, Cambodia, 2017.

55. Siem Reap Provincial Department of Planning. Siem Reap Profile on Economic and Social in Year 2019; Siem Reap Provincial Department of Planning: Siem Reap, Cambodia, 2019.

56. Trabucco, A.; Zomer, R.J.; Bossio, D.A.; van Straaten, O.; Verchot, L.V. Climate change mitigation through afforestation/reforestation: A global analysis of hydrologic impacts with four case studies. Agric. Ecosyst. Environ. 2008, 126, 81-97. [CrossRef]

57. Ramdani, F.; Moffiet, T.; Hino, M. Local Surface Temperature Change Due to Expansion of Oil Palm Plantation in Indonesia. Clim. Change 2014, 123, 189-200. [CrossRef]

58. Ellison, D.; Morris, C.E.; Locatelli, B.; Sheil, D.; Cohen, J.; Murdiyarso, D.; Gutierrez, V.; van Noordwijk, M.; Creed, I.F.; Pokorny, J.; et al. Trees, forests and water: Cool insights for a hot world. Glob. Environ. Chang. 2017, 43, 51-61. [CrossRef] 